\title{
Post Stroke Psychiatric Syndromes
}

\author{
Sukaina Rizvi ${ }^{1 *}$, Danish Kherani ${ }^{2}$, Sidra Zaheer ${ }^{3}$, Talha Naser Jilani ${ }^{4}$ and Kamil Dar ${ }^{5}$ \\ ${ }^{1}$ Newbridge Medical Center, USA \\ ${ }^{2}$ Ziauddin University, Pakistan \\ ${ }^{3}$ Dow University of health Sciences, Pakistan \\ ${ }^{4}$ Ziauddin University, Pakistan \\ ${ }^{5}$ Cambridge Health Alliance, USA
}

Submission: August 06, 2018; Published: August 17, 2018

*Corresponding author: Sukaina Rizvi, Newbridge Medical Center, USA, Email: sukainarizvi812@gmail.com

\section{Abstract}

This is a review article that highlights various psychiatric manifestations in post stroke patients. The main intent behind this review article is to discuss the possible outcomes in after stroke patients in context of their behavioral, cognitive and mood disturbances and how closely a physician should watch for these psychiatric symptoms using an integrated clinical approach to screen, diagnose, and to manage them accordingly. This can certainly impact positively on their prognosis and subsequently on their quality of life.

\section{Introduction}

According to the center of disease control statistics, stroke is the fifth leading cause of death worldwide. Lloyd- Jones, et al estimated that stroke attacks every $40 \mathrm{sec}$ and causes loss of life every 4 minute. Stroke can be defined as a complex neurological condition that occurs when there is an interruption of blood supply to a part of the brain causing brain cells to die [1]. It is a medical emergency and immediate medical care is warranted.

\section{Discussion}

Research data over the years has already established a significance of post-stroke psychiatric manifestations needs fixing, et al. states in psychiatric times that first 6 months after stroke is a time in which a person is highly vulnerable to develop these psychiatric conditions. This necessitates an obligation of a clinician and a family member as well to further explore these symptoms. We will discuss each of the possible psychiatric outcomes on individual grounds.

\section{Depression}

Post-stroke depression is a depression that occurs after the stroke and cannot be attributed to any other medical condition. Diagnostic and statistical manual of mental disorders $V$ defines depression as depressed mood or loss of pleasure along with 5 of the following for 2 weeks. These include markedly diminished interest in activities, significant weight loss when not dieting or weight gain, insomnia or hypersomnia, psychomotor retardation, loss of energy, feelings of worthlessness or excessive or guilt, diminished ability to concentrate, recurrent thoughts of death, recurrent suicidal ideation. It is highly advised that the clinician should screen patients for these symptoms after stroke as depression and stroke share a complex correlation. Various theories have been proposed to account for the higher prevalence of post-stroke depression. Depressed mood is the most frequent psychiatric manifestation after stroke with an occurrence of about $61 \%$ [2].

According to a comparative study performed in 2003, the cumulative incidence of depression in one year after stroke is approximately to be $37.8 \%$ [3]. Research publications have stated that people with left cerebral hemisphere infarction have a higher disposition to develop depression afterward $[3,4]$. A meta-analysis of 13 studies has demonstrated increased mortality in stroke patients if they encounter depression. It is of unique interest that depression in post-stroke patients differs from depression in regular population in terms of greater disability and cognitive decline [5].

Term vascular depression is often used interchangeably for post-stroke depression due to its association with cerebrovascular disease. However, some research models have shown some dissimilarities between the two. It is stated that vascular depression is correlated with small vascular ischemia while PSD is correlated with large vascular infarction. There is also some evidence of genetic modification of 5-HTTLPR as a 
neurobiological basis of occurrence of PSD and its implication in disease severity [6]. There are various modalities suggested to target these mood symptoms which include pharmacological intervention using SSRI, TCA or CNS stimulants and nonpharmacological interventions include CBT, ECT, Transcranial magnetic stimulation (TMS). However, SSRI remains as treatment of choice and role of other modalities is needed to be explored further.

\section{Pseudobulbar Affect}

Pseudobulbar affect can be defined as an emotional disturbance that causes uncontrollable crying or laughing secondary to stroke or any other neurological condition. Various hypothesis has been involved in the pathogenesis of PBA. The most influential theory states that neurophysiological pathways from cortex to pons to cerebellum are disinhibited leading to inappropriate affective expression consist of an involuntary burst of laughter or excessive tearfulness [7]. Other theories have also validated the fact that people affected with cerebellar stroke demonstrate affective lability and PBA is more common with strokes within this territory. Neurochemical pathways explain the role of various neurotransmitters and neuromodulators in PBA but most important of which are serotonin and glutamate.

This is validated by the response of PBA to SSRI and glutamate inhibitors. PBA is often misdiagnosed as depression; therefore, a clinician should keep an eye to differentiate PBA from depressive symptoms as former last few seconds to few minutes while depressive symptoms can last longer from weeks to months. Also, the other symptoms of guilt, worthlessness, fatigue, anhedonia are missing from PBA. This is also important to consider that in PBA, there is no mood component in between crying or laughing spells which is opposed to Bipolar rapid cycler which also present with laughing or crying spells but with continued mood changes [8,9].

\section{Post-Stroke Psychosis}

It is a rare manifestation after stroke, however, a recent meta-analysis by Hele Strangerland, et al. states that the prevalence of post-stroke psychosis is about 4.6 percent. Research has evidenced that people affected with post-stroke psychosis usually have lesions in the right hemisphere. In majority of cases observed in the meta-analytic study, the most common artery that was found to be involved was right middle cerebral artery [10]. A person can present with psychosis with variable presentation depending on the territory of stroke. Risk factors that can increase the likelihood of developing psychosis following a stroke are the preexistent psychiatric condition, substance use, mood disorders, intellectual disability. This risk is greater than the population with no prior history of any psychiatric condition.

\section{Anxiety}

The Diagnostic and Statistical Manual of Mental Disorders (DSM-IV) classifies anxiety disorders as a collection of syndromes including generalized anxiety disorder (GAD), panic disorder (with or without agoraphobia), agoraphobia (with or without panic), specific phobia, social phobia, obsessive-co compulsive disorder (OCD), posttraumatic stress disorder (PTSD), acute stress disorder, anxiety disorder due to a general medical condition, substance-induced anxiety disorder, and anxiety disorder not otherwise specified [11]. Anxiety is one the most common psychological disorder post stroke and is associated with an increase in dependency in the activities of daily living, reduced social networking, the severity of Post-traumatic stress disorder, worsening disability over time and mortality.

White JH et al. [12] conducted a prospective cohort study and concluded that post-stroke anxiety is positively associated with baseline PSD, baseline anxiety and less disability. Earlier it was thought that the prevalence of anxiety is low post stroke [13]. However, later, we got to know that anxiety occurs in 20$25 \%$ of the patients at any time after stroke, with Generalized anxiety disorder (GAD) and Phobic disorders being the most common types. The incidence of Post-stroke anxiety is $20 \%$ one month after stroke, increasing to $23 \%$ within five months and to $24 \%$ in 6 or more months [11].

De Wit L et. al. [14] assessed 532 patients at 2, 4 and 6 months at four rehabilitation centers using the Hospital Anxiety and Depression Scale. They find out that frequency of anxiety was $22 \%$ and $25 \%$ post-stroke at 2 and 4 months and $40 \%$ of the patients remained anxious at 6 months after stroke. GED Aiello et al. [15] in 2014 concluded that anxiety was more commonly reported than depression in the chronic stages of stroke i.e.1year post-stroke, no association of anxiety with lesion localization was found.

As far as the treatment is concerned, medications such as buspirone and paroxetine can be effective in reducing anxiety in patients with co-morbid anxiety and depression [16]. Manzoni et al. [17] because of their meta-analysis of 27 studies found relaxation training to be effective for reducing anxiety. Relaxation classes in patients post stroke led to increase motivation for participation in other activities, improve confidence, psychological functioning and quality of life [18].

\section{Dementia}

According to the American Psychiatric Association's Diagnostic and Statistical Manual of Mental Disorder poststroke cognitive impairment or dementia is generally defined as dementia occurring after Stroke with the final diagnosis should be delayed up to 6 months [19]. However, many stroke survivors develop dementia 3 months after a stroke or after recurrent stroke. Recognizing cognitive disorder in the early phase help in doing early rehabilitation and thus improving fatality by improving management [20].

Dementia in stroke involve all types of dementia whether its vascular, degenerative or mix process. In a recent study, incorporating pathological examination, vascular dementia was found in $75 \%$ of the demented stroke survivors, $25 \%$ has 
mixed pathology with either Alzheimer's type lesion or Lewy bodies [21]. Recent studies suggested that stroke survivors my trigger pathologies attributed to subcortical Vascular dementia, multi-infarct dementia, and strategic infarct dementia. Thus, the term vascular cognitive impairment was introduced, which incorporate all cognitive changes related to all causes of vascular diseases [20].

A meta-analysis done in 2009 by Pendlebury et al found that $10 \%$ of the patients were already suffering from dementia before the first stroke, 10\% develop after first stroke and 30\% developed after recurrent stroke. The prevalence of post-stroke dementia ranges from $6 \%-32 \%$ with the highest prevalence at 3 months which is about 28\% [22]. Risk factors for PSD include increasing age, severe neurological deficits, hypertension, atrial fibrillation, diabetes mellitus, myocardial infarction [19]. To prevent post-stroke dementia management of the pre-stroke risk factors, play an important role, while early treatment and rehabilitation of stroke play an important role post stroke [23].

\section{Mania}

According to DSM V, Mania can be defined as a state of an abnormally and persistently elevated, expansive or irritable mood and persistently heightened energy for at least one week, and present for most of the day. Krauthammer C, Klerman G described mania as a secondary mania if it occurs in context of neurological conditions such as stroke or due to toxic and metabolic derangements [24]. it is a rare consequence after cerebrovascular insult with very few cases reported. It has a frequency of $<1$ percent in comparison to depressive outcome in post stroke patients [25]. Post stroke mania presents with a similar presentation as primary mania, which is due to psychiatric illness. Lesions responsible for poststroke mania seems to be more related with right-sided lesions but there are also reports of mania following left-sided lesions [26].

\section{Conclusion}

Given the above review considering research articles the psychiatric consequences following a cerebrovascular accident are well understood. Despite abundant literature available, unfortunately these emotional and behavioral unsettlements are often undiscovered clinically. It is therefore imperative for a clinician to screen, recognize and to monitor these psychiatric symptoms for any progression on every follow up visit especially within first 3 years as this is time with extreme vulnerability to develop psychotic and mood symptoms. Also, neurology and psychiatry should work in collaboration to address these neuropsychiatric phenomena. There is also a need of extensive physical therapy and occupational therapy to improve clinical outcome.

\section{References}

1. Lloyd Jones D, Adams R, Carnethon M, De Simone G, Ferguson TB, et al. (2009) Heart disease and stroke statistics--2009 update: a report from the American Heart Association Statistics Committee and Stroke Statistics Subcommittee. Circulation 119(3): 480-486.

2. Dafer RM, Rao M, Shareef A, Sharma A (2008) Poststroke Depression. Top Stroke Rehabil 15(1): 13-21.

3. Aben I, Verhey F, Strik J, Lousberg R, Lodder J, et al. (2003) A comparative study into the one-year cumulative incidence of depression after stroke and myocardial infarction. J Neurol Neurosurg Psychiatry 74(5): 581-585.

4. Robinson RG, Kubos KL, Starr LB, Rao K, Price TR (1983) Mood changes in stroke patients: relationship to lesion location. Compr Psychiatry 24(6): 555566.

5. Jørgensen TS, Wium Andersen IK, Wium Andersen MK, Jørgensen MB, Prescott E, et al. (2016) Incidence of depression after stroke, and Associated risk factors and mortality outcomes, in a large cohort of Danish patients. JAMA Psychiatry 73(10): 1032-1040.

6. Robert G Robinson, Ricardo E Jorge (2015) Post-Stroke Depression: A Review. Am J Psychiatry 173(3): 221-231.

7. Ahmed A, Simmons Z (2013) Pseudobulbar affect: prevalence and management 9: 483-489.

8. Arciniegas DB, Lauterbach EC, Anderson KE, Chow TW, Flashman LA, et al. (2005) The differential diagnosis of pseudobulbar affect (PBA). Distinguishing PBA among disorders of mood and affect. Proceedings of a roundtable meeting. CNS Spectr 10(5): 1-14.

9. Ariel Miller, Hillel Pratt, Randolph B Schiffer (2014) Pseudobulbar affect: the spectrum of clinical presentations, etiologies and treatments Journal. Expert Rev Neurother 11(7): 1077-1088.

10. Helle Stangeland, Vasiliki Orgeta, Vaughan Bell (2018) Post stroke psychosis: a systematic review. J Neurol Neurosurg Psychiatry 89(8): 879-885.

11. Campbell Burton CA, Murray J, Holmes J, Astin F, Greenwood D, et al. (2013) Frequency of anxiety after stroke: a systematic review and meta-analysis of observational studies. Int Jr Stroke 8(7): 545-559.

12. White JH, Attia J, Sturm J, Carter G, Magin P (2014) Predictors of depression and anxiety in community dwelling stroke survivors: a cohort study. Disabil Rehabil 36(23): 1975-1982.

13. House A, Dennis M, Mogridge L, Warlow C, Hawton K, et al. (1991) Mood disorders in the year after first stroke. Br J Psychiatry 158: 8392.

14. De Wit L, Putman K, Baert I, Lincoln NB, Angst F, et al. (2008) Anxiety and depression in the first six months after stroke. A longitudinal multicentre study. Disabil Rehabil 30(24): 1858-1866.

15. D Aniello GE, Scarpina F, Mauro A, Mori I, Castelnuovo G, et al. (2014) Characteristics of anxiety and psychological well-being in chronic post-stroke patients. J Neurol Sci 338(1-2): 191-196.

16. Campbell Burton CA, Holmes J, Murray J, Gillespie D, Lightbody CE, et al. (2011) Interventions for treating anxiety after stroke. Cochrane Database Syst Rev 12: CD008860.

17. Manzoni GM, Pagnini F, Castelnuovo G, Molinari E (2008) Relaxation training for anxiety: a ten-years systematic review with meta-analysis. BMC Psychiatry 8: 41.

18. Carin Levy G, Kendall M, Young A, Mead G (2009) The psychosocial effects of exercise and relaxation classes for persons surviving a stroke. Can J Occup Ther 76(2): 73-80.

19. Gwo Chi Hu, Yi-Min Chen (2017) Post-stroke Dementia: Epidemiology, Mechanisms and Management. International Journal of Gerontology 11(4): 210-214. 
20. Kalaria RN, Akinyemi R, Ihara M (2016) Stroke injury, cognitive impairment and vascular dementia. Biochim Biophys Acta 1862 (5) 915-925.

21. Ihara M, Kalaria RN (2014) Understanding and preventing the development of post-stroke dementia. Expert Rev Neurother 14(9): 1067-1077.

22. Pendlebury ST, Rothwell PM (2009) Prevalence, incidence, and factors associated with pre-stroke and post-stroke dementia: a systematic review and meta-analysis. Lancet Neurol 8(11): 1006-1018.

23. Portegies ML, Wolters FJ, Hofman A, Ikram MK, Koudstaal PJ, et al (2016) Prestroke Vascular Pathology and the Risk of Recurrent Stroke and Poststroke Dementia. 47 (8): 2119-2122.
24. Krauthammer C, Klerman G (1978) Secondary mania. Manic syndromes associated with antecedent physical illness or drugs. Arch Gen Psychiatry 35: 1333-1339.

25. Jeff C Huffman, Theodore A Stern (2003) Poststroke Neuropsychiatric Symptoms and pseudo-seizures: A discussion. Prim Care Companion J Clin Psychiatry 5(2): 85-88.

26. Abhishek Pathak, Mona Srivastava (2014) Post-Stroke Mania-A Case Report, ASEAN Journal of Psychiatry 15(2): 209-212.

\section{Your next submission with Juniper Publishers will reach you the below assets}

- Quality Editorial service

- Swift Peer Review

- Reprints availability

- E-prints Service

- Manuscript Podcast for convenient understanding

- Global attainment for your research

- Manuscript accessibility in different formats

( Pdf, E-pub, Full Text, Audio)

- Unceasing customer service

Track the below URL for one-step submission https://juniperpublishers.com/online-submission.php 